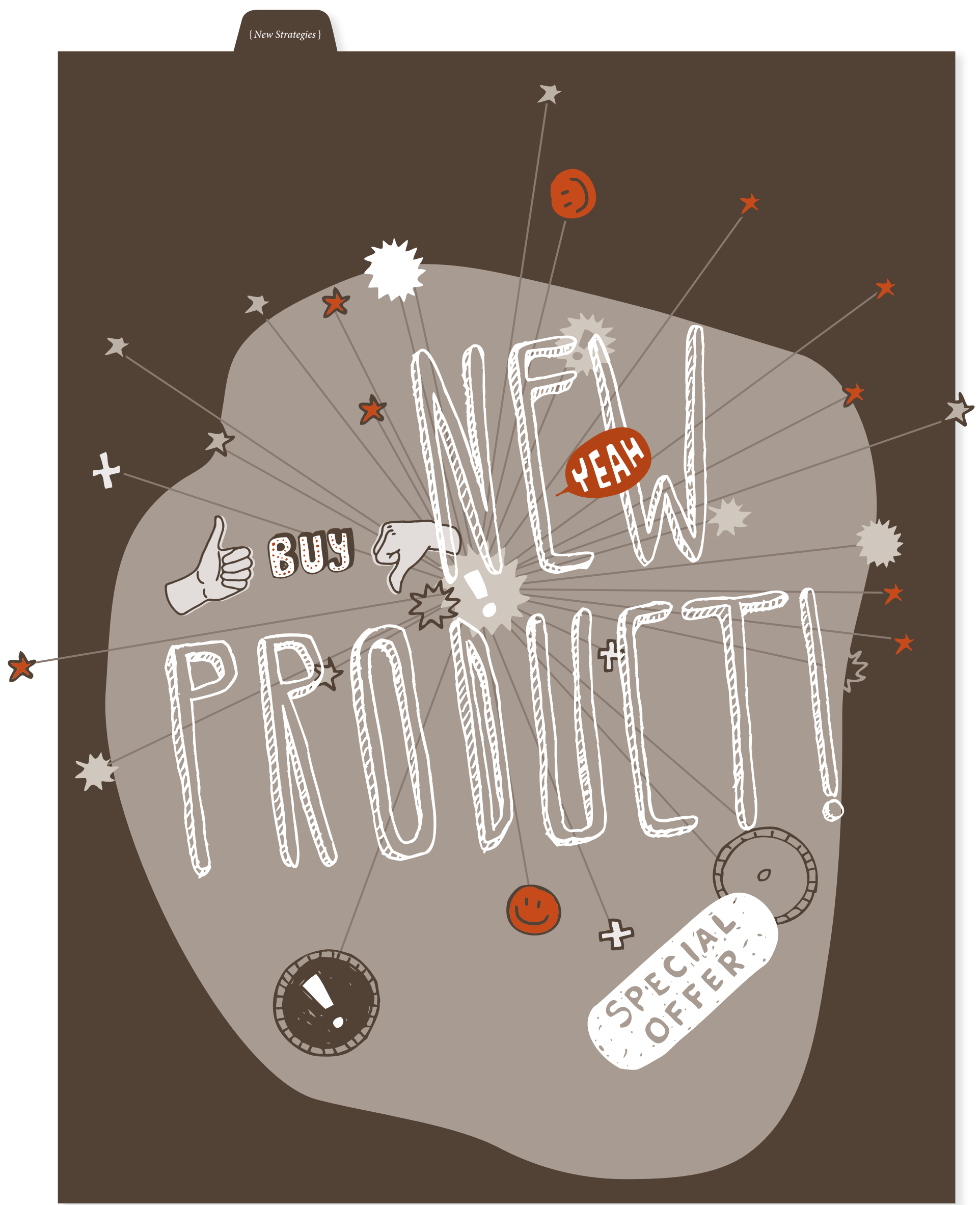




\title{
PREPARING FOR THE ADOPTION OF THE NEW ARRIVAL
}

\author{
Raquel Castaño, Mita Sujan, Manish Kacker and Harish Sujan
}

\begin{abstract}
The emotional state of many expecting parents shifts from unbridled joy to anxiety as the reality of learning to care for a newborn and forsaking their current lifestyle sinks in. Similarly, consumers have different concerns when they first hear about a new product compared to the time when they consider buying it. If the buying decision is in the distant future, consumers are primarily concerned with the benefits derived from using the product, such as how the product performs and symbolic benefits of owning the new product. As the buying decision draws closer, consumers shift attention to cost-related issues, such as how long will it take to learn how to use the product or how much will it cost to maintain and use it. Executing a two-phased communication strategy by management that is synchronized with this shift in mental processes by first emphasizing new product benefits and features and later focusing on the practical aspects of using the innovation can have a beneficial impact on both organizational performance and consumer welfare.
\end{abstract}

In keeping with its heritage of innovation, Michelin has developed the Tweel, a no-air combination tire and wheel technology. The Tweel performs well on uneven terrain, buckling when it goes over bumps and obstacles and then rapidly recovering its original shape. Consumers are frequently confronted with such innovations that require them to adopt new behaviors and discontinue past habits. While consumers are initially excited by the performance potential of these new products, they become increasingly concerned with the uncertainties associated with the costs of adopting such products and gravitate back to familiar options as the time to make an adoption decision approaches. Our research provides a strategy managers can use during the roll out phase of new product introductions to proactively manage these shifting consumer perceptions with the goal of increasing consumers' adoption and satisfaction with new products.

Why do consumers move from approach to avoidance for new products? Research examining how people visualize a near and distant future provides the answer.
When a person is considering an action in the distant future, the focus is on the benefits and the positive outcomes of the decision. However, as the action draws near, the decision maker focuses on the efforts and costs of the action and the downside risks of the option. Temporal construal theory also explains why early product concept test results often provide unreliable data on product acceptance. Product preferences, obtained when consumers perceive the product as being far from market, overestimate the benefit related features of the product and underestimate the cost related features, including the challenges of learning and using the product.

Early product concept test results may provide unreliable data on product acceptance. Product preferences, obtained when consumers perceive the product as being far from market, often overestimate the benefit related features of the product and underestimate the cost-related features, including the challenges of learning and using the product.

Consumers are unsure about the characteristics of new products introduced to the market. The term "really new product", refers to new technologies perceived by consumers as innovations with high uncertainty and risk levels. Important sources of uncertainty associated with really new products or services include:

a) performance uncertainty - What is the expected utility of the product? How useful will the product be to me?

b) symbolic uncertainty - How socially desirable is the product? How will others see me if I adopt this product?

c) switching-cost uncertainty - How difficult will it be to switch from using the current product to the new product? Will I be able to learn how to use it?

d) affective uncertainty - What is the extent of emotional attachment to existing options? How will I feel if I forgo the old?

\section{THE AUTHORS}

Raquel Castaño, Professor of Marketing at EGADE Tecnológico de Monterrey, México rcastano@itesm.mx

Mita Sujan, msujan@tulane.edu, and Harish Sujan, hsujan@tulane.edu are professors of Marketing at A. B. Freeman School of Business, Tulane University, New Orleans (LA)

\section{Manish Kacker,}

Associate Professor of Marketing, AIC Professor of Strategic Business Studies, DeGroote School of Business, McMaster University, Hamilton, Canada mkacker@mcmaster.ca

The article is adapted with permission from the Journal of Marketing Research published by the American Marketing Association: Raquel Castaño, Mita Sujan, Manish Kacker, Harish Sujan: "Managing Consumer Uncertainty in the Adoption of New Products: Temporal Distance and Mental Simulation", Vol. XLV (June 2008), pp. 320 - 336. 


\section{》) Systematic shifts in communication strategy from preannouncements to market launch can reduce consumer perceptions of uncertainty and increase adoption levels and satisfaction with new product adoption. «}

What is of critical importance in designing effective communication strategies for launching new products is accounting for how the relative importance of these different types of uncertainties shifts during the different phases of the decision making process for new products (Refer to Figure 1).

Our empirical research (Study 1) establishes that the types of uncertainties that dominate consumer thinking change as the product adoption decision progresses. When adoption is in the distant future, consumers are primarily concerned with benefit-related uncertainties, such as performance benefit (how will the tires perform?) and symbolic benefit (e.g., what will others think of the new tires?) uncertainties. As the adoption decision approaches, consumers shift their attention to costrelated uncertainties, such as switching costs (e.g., how easy will it be learn to drive on Tweels or maintain them?) and affective (e.g., how much will I miss my traditional pneumatic tires?) uncertainties.

It is fundamental to understand the concerns of consumers in each phase of the decision making process for new products in order to design a more effective communication strategy for each phase. Consumers first deliberate about uncertainties related to the performance and symbolic features of new products and only later consider the challenges and uncertainties about learning new technologies and their feelings about forgoing the familiar.

Organizations can adapt their communication strategies to address these shifting consumer concerns. Research on motivating behaviors suggests that people can be motivated to visualize the future in two ways, one by simulating the results of an action, and two by simulat- ing the process of taking the action. For example, a consumer deciding whether or not to buy a new technology phone could imagine the outcomes (the "whys") of using the new technology phone (e.g., access to e-mail, improved web-browsing). That is the consumer could simulate the reasons for switching from an old cell phone to the new technology. The person could also imagine the process (the "how-tos") of using the new phone (e.g., imagine transferring the data from the computer to the phone, downloading applications, calling the company to resolve difficulties, budgeting for the increased monthly fee). That is, the consumer could simulate the process of switching from an old cell phone to the new technology. Which type of simulation works better for communicating about the new phone?

Our research (Study 2) finds that preannouncements for new products due to be launched in the relatively distant future should guide consumers to elaborate on the "whys" of adoption (e.g., new and better technology). In contrast, communication strategies for product launches in the relatively near future should encourage consumers to elaborate on the "how-tos" of adoption (understanding the costs and operating procedures for the product). Synchronizing communication strategies with temporal distance to adoption increases the actual product adoption rates and equally importantly, such temporal synchronization increases satisfaction with the product after adoption.

Preannouncements that promote the visualization of the outcomes or benefits of using the new product should be replaced by communications at market entry that help consumers visualize the concrete challenges and the process or steps of successfully adopting the new technology.

Thus, we find that if communication efforts are properly focused over time, they will reduce the specific uncertainties and risks that consumers consider during the different phases of deliberation and purchase of new products. In addition, in our research (Study 3 ) we find these communication efforts are more efficacious for more-new versus less-new products.

Preannouncements should promote visualizing the benefits of using the new product. How can this be best achieved? First, preannouncements should encourage distant thinking with phrases such as "in the making" 
Figure 1:

\section{KEY QUESTIONS AND RESEARCH DESIGN}

Do consumers' concerns shift as the time to adoption nears?

\section{STUDY 1}

Experimental Study

Temporal Frame

(Near Future vs. Distant Future)

effects on

- Uncertainty thoughts

- Emotions

- Behavioral Intentions

Longitudinal Study

Temporal Frame

(Near Future vs. Distant Future)

effects on

- Uncertainty thoughts

- Emotions

- Behavioral Intentions
What communication strategies

are effective during the pre-

announcement phase and the

market entry phase of new

products?
Are these communication strategies equally effective in promoting adoption at all levels of product newness?

\section{STUDY 3}

Experimental Study

Temporal Frame

(Near Future vs. Distant Future)

Type of Communication Strategy

(Process Simulation vs.

Outcome Simulation)

effects on

- Uncertainty thoughts

- Emotions

- Behavioral Intentions

- Adoption

- Post-consumption Satisfaction
Experimental Study

Temporal Frame

(Near Future vs. Distant Future)

$\times$

Type of Communication Strategy (Process Simulation vs. Outcome Simulation)

Level of Product Newness

(More vs. Less)

effects on

- Uncertainty thoughts

- Behavioral Intentions

\section{STUDY $2 \mathrm{~A}$}

Experimental Study

Temporal Frame

(Near Future vs. Distant Future)

Type of Communication Strategy (Process Simulation vs. Outcome Simulation vs. Control) effects on

- Uncertainty thoughts

- Behavioral Intentions

- Behavioral Intentions

(delayed) 
$\{$ Study 1$\}$

\section{TEMPORAL DISTANCE AND THE ADOPTION PROCESS FOR NEW PRODUCTS}

The purpose of Study 1 was to assess how the relative importance of different types of uncertainties associated with the adoption of new products change over time with both experimental and longitudinal studies. We investigated the adoption of a newly offered virtual class in a Mexican university. We conducted a pretest to measure perceived newness. For the participating students, the average of the newness measure for a virtual course was high (8.56 on a ten-point scale), and none had previously taken a virtual course. For the experimental study we used a one-way analysis of variance (ANOVA) (time frame: near versus distant) between-subjects design and for the longitudinal study a one-way ANOVA (temporal distance: near versus distant) repeated measures design. In both cases we measured the effects of temporal frame (near future versus distant future) on uncertainty thoughts, emotions and behavioral intentions. Study 1 demonstrates that the uncertainties of concern in the adoption of a new product shift from performance and symbolic uncertainties in the distant future to switching cost and affective uncertainties and anxiety in the near future. Furthermore, behavioral intentions decline as the time to make an adoption decision approaches. The converging evidence from the experimental and longitudinal studies adds to previous experimental work on intertemporal choice and validates the view that people are able to simulate adopting an unfamiliar product or service in the near and distant futures. Figure 3 illustrates these results.

"new technology breakthroughs in our RandD being prepared for market introduction". Then, preannouncements should be focused on consumer goals and benefits conveyed at an abstract level. This can be achieved by communication rich in the contextual details surrounding the new product, achieved by depicting typical consumers in typical situations enjoying the benefits of the new introduction. Anticipations of the benefits are best achieved via landscape shots taken at some distance from the product so as to focus on the benefits created by the product, rather than the product itself.
$\{$ Study 2$\}$

\section{MENTAL SIMULATION AND TEMPORAL DISTANCE}

The purpose of Study 2 was to test communication strategies that were likely to reduce the different types of uncertainties associated with new product adoption at different temporal distances to adoption. As in Study 1 , adopting a newly offered virtual class in a Mexican university served as the context. The experiment was a $2 \times 2$ between-subjects design, crossing focus of simulation (outcome versus process simulation) with temporal frame (near future versus distant future). Participants were randomly assigned to one of the four conditions. Participants were presented with the written description of the virtual course and imagined themselves making the decision whether to enroll in a virtual course tomorrow (near-future condition) or next year (distant-future condition). Half of the participants engaged in outcomeoriented imaginations of the benefits of enrolling in a virtual course, and the other half engaged in processoriented imaginations of working through the constraints of a virtual course. Actual enrollment data were observed for all participants $25-28$ days later. Postconsumption satisfaction was recorded two weeks after the start of classes. Results show that process simulation directed at helping consumers reduce switching cost uncertainties and affective uncertainties is constructive when the adoption decision for a new product is in the near future; meanwhile, outcome simulation directed at reducing performance and symbolic uncertainty is productive when the adoption decision is temporally distant. Furthermore, students who had considered adopting a virtual course believing that the decision was imminent and had simulated the process of dealing with the constraints of the new course format were more likely to register in a virtual course $25-28$ days later and appeared to be the most satisfied with the course after the first two weeks of the course. Figure 3 illustrates these results.

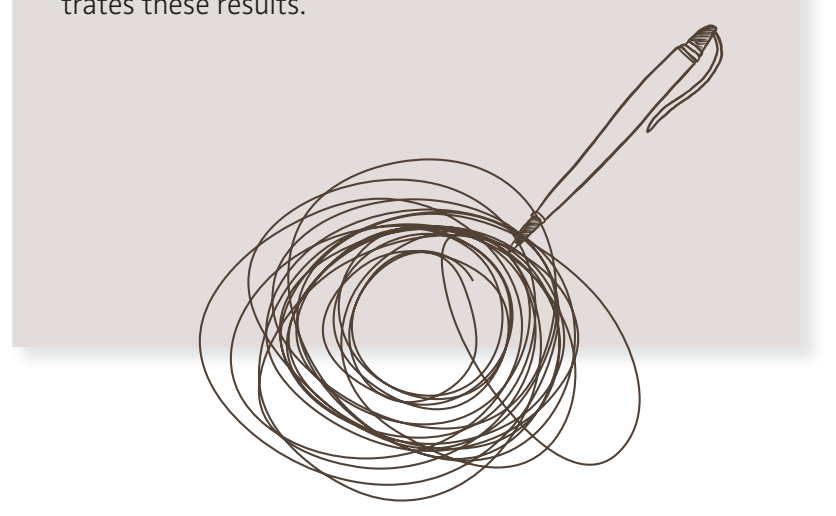




\section{ADOPTION PROCESS FOR MORE-NEW VERSUS LESS-NEW PRODUCTS}

In Study 3, we examined the efficacy of simulation strategies for two levels of product newness. We examined adoption intentions for car concepts that varied in newness (active-cruise control car versus automatic car). The experiment was a $2 \times 2 \times 2$ between subjects design, crossing focus of simulation (outcome versus process simulation) with temporal frame (near future versus distant future) and newness of the concept (more new versus less new). Students at a Mexican university participated in the experiment and were randomly assigned to one of the eight experimental conditions. Participants were presented with one of two car descriptions that varied in the degree of newness. Before reading the description they were told to imagine themselves in a situation in which they needed to make the decision of whether to buy and use the car either next week or next year and to imagine either the benefits or the process of buying and using the car. Study 3 validates the position that the importance of uncertainty management in new product adoption is contingent on degree of newness and more important for really new products relative to incrementally new products.

For robotic vacuum cleaners the landscape shot is of a clean room, the IRobot is in a distant corner at work, and a relaxed person is on a couch. These suggestions are congruent with the successful launch of the iPhone by Apple in 2007. The iPhone was first announced with "in the making" announcements. Apple's communication strategy highlighted the benefits of adopting the iPhone. Apple's television commercials and website focused on, for example, the innovative and abstract benefit of individualization and entertainment that the revolutionary touch-screen interface and multimedia capabilities afforded the consumer.

Preannouncements should be structured to include phrases such as "in the making" to promote a distant time horizon, and use landscape shots that depict the benefits created by the product rather than on the product itself.
At the time of market entry, communication messages should help consumers visualize the concrete challenges and steps of successfully adopting the new technology. How can this be best achieved? First, market launch announcements should encourage proximate thinking with phrases such as "now available for the first time". Then, market launch announcements should be focused on procedures for easing adoption conveyed at a very concrete level. This can be achieved by demonstrations focused on the product itself, achieved by depicting typical consumers in typical situations actually interacting with the new introduction. Anticipations of usability are best achieved via close-up shots of the product so as to focus on the mechanics of use of the product. So for robotic vacuum cleaners the close-up shot is of a consumer pressing the "clean" button to make the IRobot spin. Consistent with these suggestions we see that as the launch of the iPhone drew closer, Apple's communication strategy shifted to emphasizing the "how-tos" of adoption - television commercials and the website featured close-up demonstrations of actual use of the phone and service options by consumers.

Market entry advertising should be structured to include phrases such as, "now in market for the first time", to promote a proximate time horizon and should use close-up shots that demonstrate how the product can be easily operated by the consumer.

There is a widespread awareness across companies and industries of the need to develop products that are really novel as a means to ensure profitability in difficult business environments. Hence, the execution of the introduction of a new product becomes a critical task, especially as the level of product newness increases. The communication dimensions of launch implementations are a crucial part of success - tailoring the communication strategy to the proximity of the product launch and adoption can enable innovative firms to fully capture the fruits of their labor.

Our ideas have public policy implications as well. The ideas can help policymakers generate popular acceptance for new initiatives that substantially depart from the status quo by introducing the "whys" of change before the "hows" of change.

Our ideas have public policy implications as well. The ideas can help policymakers generate popular acceptance of new initiatives that substantially depart from the status quo. Based on our findings, initial communications about big policy changes, for example, around health care in the United States, should encourage citizens to simu-

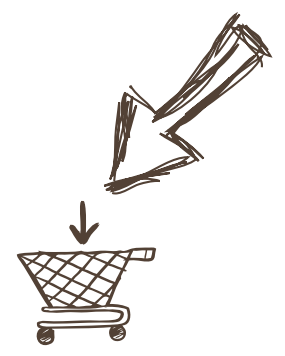


Figure 2:

\section{Q AND A IN NEW PRODUCT INTRODUCTIONS}

Do consumers' concerns shift as the time to adoption nears?

\section{WHEN ADOPTION IS DISTANT}

Performance benefits and symbolic benefits are paramount.

\section{AS THE DECISION NEARS}

Learning and switching costs are paramount.

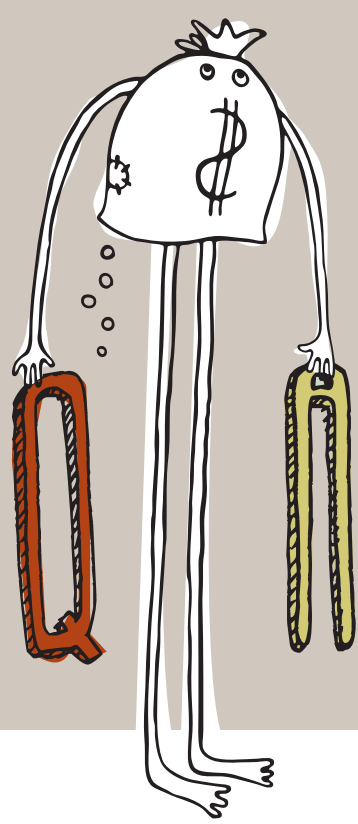

What communication strategies are effective during the preannouncement phase and the market entry phase of new products?

\section{WHEN ADOPTION IS DISTANT}

Preannouncements should promote visualization of the outcomes (the "whys") of adoption using landscape shots focused on the performance and symbolic benefits created by the product, rather than on the product itself.

\section{AS THE DECISION NEARS}

Market entry ads should promote the visualization of the process (the "hows") of adoption using close-up shots that demonstrate actual product use.
Are these communication strategies equally effective in promoting adoption at all levels of product newness?

While these communication strategies are helpful in the launch of all new products, their efficacy increases as product newness increases. 


\section{FURTHER READING}

late and debate the "whys" of adoption to encourage buy-in to the new policies. Closer to the policy implementation, communications must help citizens manoeuver the "how-tos" of adoption for successful implementation of the new plans. Carefully tailored communication strategies that fit the timing of the launch of new product or policy initiatives can have a beneficial impact on both organizational performance and consumer welfare. •

FIGURE 3:

Overall Pattern of Uncertainties, Intentions and Satisfaction

Overall Pattern of Uncertainties based on Temporal Distance

--Switching -- Affective - Performance - Symbolic

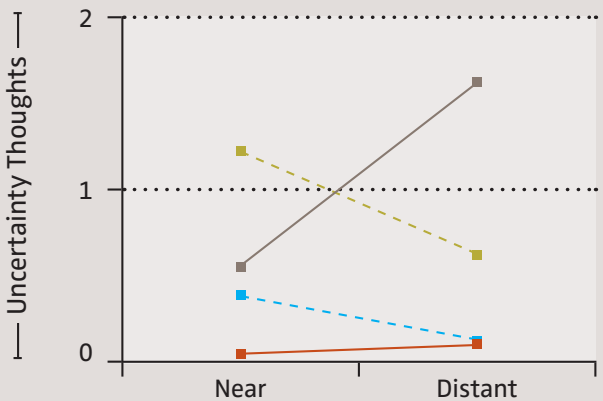

Overall Pattern of Behavioral Intentions and Satisfaction based on Matching Process versus Outcome Communication Strategies to Temporal Distance

- Process $\quad$ Outcome

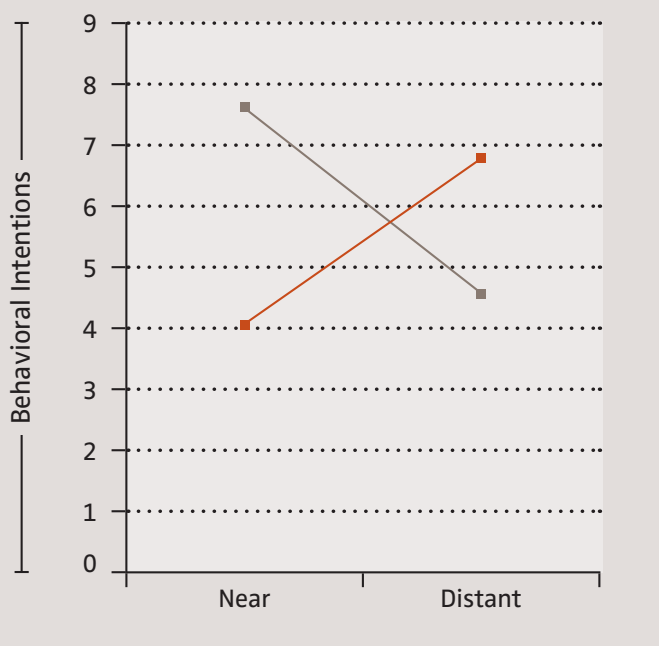

Hoeffler, Steve (2003):

"Measuring Preferences for Really New Products", Journal of Marketing Research, 40 (4), pp. $406-421$.

Taylor, Shelley E., Lien B. Pham, Inna D. Rivkin, and David A. Armor (1998):

"Harnessing the Imagination, Mental simulation, Self-regulation, and Coping",

American Psychologist,

53 (4), pp. $429-439$.

Thompson, Debora V., Rebecca W. Hamilton, and Roland T. Rust (2005):

"Feature Fatigue: When Product Capabilities Become Too Much of a Good Thing", Journal of Marketing Research, 42 (November), pp. $431-442$.

Trope, Yaacov and Nira Liberman (2003): "Temporal Construal", Psychological Review, 110 (3), pp. $403-421$.

\section{KEYWORDS:}

Innovation Management, New Products, Preannouncements, Roll-Out, Communication Strategies, Construal Theory 